\title{
The influence of Emotional Intelligence and Adaptability on Lecturers' Performance in Private Universities (Higher Private Education Institutions) in Timor-Leste
}

\author{
Armindo Coelho ${ }^{1}$, Alvaro Menezes Amaral ${ }^{\mathbf{2}}$ and Carla Alexandra da Costa ${ }^{\mathbf{3}}$ \\ Graduate School, Dili Institute of Technology (DIT), Timor-Leste. \\ Email:armindo.coelho80@gmail.com,alvavomenezesamaral@gmail.com,calexandra56@yahoo.com
}

\begin{abstract}
Nowadays, education continues to rapidly change and develop. The development of education always becomes a competition with related education competitors, especially in higher education. To achieve a better quality of education, lecturers or teachers in high education institutions must be able to master teaching materials, teaching methodology, and particularly the ability of emotional intelligence (EI), also adaptability to teachers' performance. This research was conducted at private universities in Timor-Leste, with a population of 1690 lecturers. This study used a survey in the questionnaire and the hypotheses were tested using Smart-PLS 3.0 tool. The result indicated that emotional intelligence has a positive significant impact on adaptability and it is shown in the t-statistic correlation value on working performances. The best education results bar for lecturers' needs to dominate the courses that can be taught to students, teaching styles. Lecturer job performance is influenced by individual factors such as performance, skills, abilities, and thinking. Other factors such as the influence of work performance, such as environment, leadership, university structure, technological aesthetics and culture. Therefore, the practical implication from this research contributed to the government of Timor-Leste particularly the ministry of higher education institutions to provide further attention for the development of human resources, building lecturers capabilities and professionalism in higher private education institutions in TimorLeste. This study also contributed to the educational institutions especially for higher private education institutions to fully pay attention to develop their lecturers' capabilities to provide better services to university students in Timor-Leste.
\end{abstract}

Keywords: Emotional Intelligence and Adaptability to Lecturers' work Performance

\section{Introduction}

Lecturers or teachers at the university have important roles and occupations in a particular level of the job at the higher education system in a country (Sakyi and Agomor, 2020). For the sake of better teaching, lecturers do not require only having high academic qualifications, but they need to have training on EI (Emotional Intelligence). Lecturers tend to score high on emotional intelligence; thus, they could teach students more efficiently and effectively (Cladera, 2020). Lecturers need to perform better in their performances. To realize the better performances of lecturers, some indicators that have been developed previously to be considered such as quality of work outcomes and quantity of teachers' loading work. Therefore, the lecturers' performance (outcome work and a whole working process) could be assessed from the input or suggestions which is assessed by the top management in the university. Universities need to create competitive advantages that are different from other competitors to maintain success in the competitive environment. (Miotto, Del-Castillo-Feito and Blanco-González, 2020) illustrated that the determinant significant factor for employees' performances and ready for the competitiveness advantages is the human resources' capabilities. For the better teachers' performances and teaching and learning process, lecturers are required to master the teaching materials and other effective skills. This skill required two dimensions of thinking and feeling. These abilities or skills are called EI (Emotional Intelligence) (Sembiring, et, al., 2020). Emotional intelligence is the ability to understand, use, and manage your own emotions in positive ways to relieve stress, communicate effectively, empathize with others, overcome challenges and defuse conflict (Sembiring, et, al., 2020).

Some universities in Timor-Leste were closed down, because there were not enough human resources to offer into the qualifying academic process of teaching and learning. Based on the assessment was conducted by the Ministry of Education in 2016 and 2019, the result showed that there were 33 higher education institutions registered since the year 2004/2005. However, only 14 higher education institutions were presented to the accreditation process in 2008. Half of the higher education institutions registered have been withdrawn. Among the 14 higher education institutions, there was only 1 public university and 4 high private institutions were qualified for the institutional accreditations in 2008, and the reamaining were on probations. In the probation process also there were two universities rejected directly, because the institutions did not meet the minimum accreditations requirements. The main requirements of the accreditations are mainly the human resources in the university, particularly lecturers' qualifications. In 2009, the ministry of education reconducted the second accreditation process for those universities that under probations. The result 
showed that there was one university and four higher education institutions qualified for the accreditation and the other two remained under probation. In 2013, these two universities were qualified for accreditation (Freitas, 2015).

These cases showed that the matter of teaching at schools particularly in higher education institutions is a huge concern in Timor-Leste. It started in 2015 when the ANAA has conducted the second institutional accreditation and started subsequently the department (major of study) accreditations. The total of 200 major of study programs, 105 study programs have achieved the programmatic accreditation. There were $80 \%$ of study programs obtained grade C, $20 \%$ were B and none of the study programs reached A. Based on the assessment indicators, the big issues were faced by the higher education institutions was the human resources in terms of lecturers' qualifications and capabilities. Therefore, a higher education institution needs to foster their lecturers' capabilities to ensure the quality and sustainability of high education. Further, the most important to ensure the quality and sustainability of high education is teachers' performances. The better performances of lecturers will enhance the quality of the educations institutions and also will appear as competitions between one university and other high education institutions.

Teachers' performance is one of the indicator to measure a teacher's role and responsibility in the school (Sembiring, et, al., 2020). This is to strengthen the argument that a teacher's performance has a positive effect on the organization's or higher education institution's performance as well. Therefore, this study focused on teachers' EI, adaptability and working performances. This means EI and adaptability will have significant effect on lecturers' performances. In this study, researchers wanted to measure and analyze lecturers' performance according to the dimensions of emotional intelligence and its adaptation to the teaching profession in private universities. And also this research needs to look at emotional intelligence and lecturer performance and needs to test the effectiveness of adaptation mediation and the relationship between emotional intelligence and the work performance of lecturers at a private university in Timor-Leste.

Furthermore, the researcher wanted to identify the items or indicators of lecturers' performances from dimensions of EI and adaptability of the profession of lecturers. Also, this study deeply investigated regarding a significant effect of EI on lecturers' performance. This study aims to identify the performance of lecturers in adaptation and emotional intelligence as well as the performance of lecturers in universities in Timor-Leste. Thus, this study will determine the effect of emotional intelligence and adaptability on lecturer performance. The researchers hope that this study could offer significant theoretical and practical implications in this area.

Therefore, the objectives of this study are as follows: (1) to identify and explain the influence of EI and adaptability to lecturers' performance. (2) to investigate the influence of EI on adaptability.(3) to identify the significant effect of adaptability as a mediation between EI and lecturers' performance.

\section{Literature Review}

\subsection{Lecturer Work Performance}

Lecturers' performance is a result of the quality and quantity of an individual as lecturers' responsibility to serve their work (Abu Elnasr, et, al., 2019). These response abilities are teaching, supervise the students, and conduct administration work. These works mentioned previously are the main work of a lecturer. A lecturer requires to provide a guide to university students to find better solutions to every problem that students have confronted (Castillo and Del valle, 2017) Academic performance is an aseessment result for every lecturer which based on their job description. Lecturer academic performance is influenced by an individual factor as follows: self-motivation, creativity, self capabilities, critical thinking, environment, leadership, institutional structure, technology strategy and also culture (Adika and Kwanya, 2020). The management team in higher education require to praise and consider the work that has been done by all lecturers, also build good transparency in communication and provide subsidies for lecturers (Yimin, et, al., 2019).

This is because working performance is an important requirement as the result of the success of the institution to achieve the vision of the institution (Ni Made,et, al., 2016). Working performance is a variable of individual level. This concept is different from another concept that embraces the institutional performance and national performance which are variables for a superior level (Kivipõld, Türk, et, al., 2020). Therefore, the lecturer professional performance is a result of the assessment of lecturer's capabilities. These capabilities are including teaching well to students, and domain competent of pedagogical teaching and techniques in teaching students based on the institutional pattern. As the high education institutions, lecturers are entitled to teach based on the higher institution pattern which is accredited (Mekoth, et, al., 2016). Lecturer academic performance is influenced by an individual factor as follows: self-motivation, creativity, self capabilities, critical thinking, environment, leadership, institutional structure, technology strategy, and also culture (Abu, 2019).

\subsection{Emotional Intelligence (EI)}

Emotional intelligence refers to an individual's ability to help understand and regulate feelings, emotions, and emotional knowledge to encourage emotional growth and individual intelligence. (Miguel Ángel Sastre Castillo, 2018). The emotion is the capability to regulate self-control or feelings in the work, communication, and emotional knowledge to be able to adoptability in the community or society. Nowadays, social relationships are correlated with emotional intelligence to all environments, whether the relationships between individuals and others in the workplace or a community because those people who score high on emotional intelligence tend to perceive that expressing emotions is required by their job the likelihood for promotion and succeess. This is also can be proved that leaders who are highly emotionally intelligent tend to exhibit emotional labor in the workplace and community by maintaining positive temperaments when interacting with others 
(Srivastava and Dey, 2020). Emotional Intelligence is also recommended to be positively significant to the conceptual behavior for lecturers (Wong, et, al., 2012).

EI (Emotional intelligence) is a way of learning a self emotion, because everyone does not live with a complete emotion, especially on feelings. People must learn how to have an emotional process in an environment. The Emotional intelligence of lecturer performance is an important factor that contributes to positive behavior as the lecturer's competent concept. It is also to know the emotion between a lecturer with other lecturer's (Darvishmotevali et al., 2018). The Emotional intelligence defines as an emotionally intelligent type that deals with the ability of an individual to regulate his/her personal, and others' emotions and feelings (Sembiring, et, al., 2020). Emotional intelligence has four items, they are self-emotional, other emotional, regulation of emotions, and use of emotional (Sony and Mekoth, 2016). People who score high on emotional intelligence and soft skills tend to have the ability to communicate with the superior, critical thinking, and eager to learn from others. This means an individual with emotionally intelligent and good manner tend to achieve their objectives of working, as they tend to have good emotions and feeling in case of solving the problems in the workplace (Sembiring, et, al., 2020).

Emotional intelligence also defines as an emotionally intelligent type that deals with the ability of an individual to regulate his/her personal or problems in the workplace, and able to regulate their mood and communication with others' emotions and feelings (Treasa Gianfranco, 2017). EI is the profound concept of "social intelligence" which is firstly identified by (Wong, et, al., 2012). The definition of social intelligence is the ability to regulate his/her personal to make decisions for better human relationships. Social intelligence consists of each one intrapersonal (Mekoth, et, al., 2016). Emotional intelligence is apart from social intelligence that involves an individual's emotion with others' emotions and feelings. According to (Treasa Gianfranco, 2017) Emotional intelligence defines as an emotionally intelligent type that deals with the ability of an individual to regulate his/her personal (to manage our emotional life with intelligence), and others' emotions and feelings (the appropriateness of emotion and its expression). She also mentioned that social intelligence is an intelligent type that has a relation with the side of life to respect each other and motivate each other for the effects of working in the workplace.

\subsection{Adaptability}

Adaptability defines as a skill that refers to the ability of a person to change his actions or approach to do things to suit a new situation in their workplace (Darvishmotevali et al., 2018). The definition of adaptability generally means the ability of a person to solve the pressure and limitations at the workplace to sustain the work. Adaptability is the quality of being able to adjust to new conditions. The adaptability theory in the field of organizational management can in general be seen as an ability to change something (Riane Johnly Pio, 2018). Therefore, adaptability means an art behavior of the ability of every lecturer to be able to make a better change in their workplace. Factors that influence working adaptability are emotional intelligence and ability of adaptability (Dipboye, 2018).

Adaptability is the responsibility of an individual to regulate his/her emotion and behavior in order to respond to the change in the situation to be suited to the new situation (Gupta, 2018). Adaptability can cause a person to have better change in his/her workplace to make them feel comfortable with their work. Therefore, lecturers could concentrate on their work, then it could enhance their adaptability in the workplace. Lecturers require to make their adaptability as a competent substance in the domain with their work performances. Lecturers need to have adaptation in their workplace and teaching; therefore, students can understand it well. Lecturers also have to adapt to with the rules and regulations that institutions have set up, for instance, come to work on time as well as oof to work on time. Therefore, it could fulfill the vision of the institutions.

\subsection{Emotional Intelligence and Lecturers Performance}

Emotional intelligence is an important key and resource for lecturers to enhance their performances in higher private education institutions (Collie, et, al., 2020). Every lecturer requires to work hard, if lecturers do not work hard, there will be a negative impact on the institutions (Zulfadil, 2019a). Lecturers are the high educational institutions' forefront guards for the succeess of the institution (Rajalakshmi, et, al., 2018). If there is a working pressure for lecturers, the impact is lecturers could not be able to perform well. Therefore, lecture capabilities and adaptability must be the priority at forefront of the institutions. There is evidences that the lecturer's performance has a correlates with adaptability between lecturers and work productivity.

\subsection{Emotional Intelligence and Lecturers Adaptability}

Emotional intelligence (EI) is a dimension multi-concept (Mittal, 2020). Adaptability is also important and it deserves to be further investigated in its relationships with emotional intelligence. This research is important because emotional intelligence plays an important factor to influence adaptability. Emotional intelligence could be the main contributor factor to adaptability, particularly the contribution to the positive behavior (Goleman, et, al., 20018). Previous research was also exploring the adaptability of emotional intelligence (Ala'aldin, et, al., 2020). Employees who score high on emotional intelligence tend to enhance the organization's quality of adaptability, and tend to be have better skills on services the necessity of the clients (Miguel Ángel Sastre Castillo, 2018). Emotional intelligence which has a significant influence with lecturers' adaptability tends to a significant effect on working performance. The ability of adaptability and emotional intelligence also influence the lecturers performance (Sony \&Mekoth, 2016). The competition on individuals' emotional intelligence that tends to make people curious to enhance positive behavior and obtain the good result of their behavior. An individual's emotional intelligence tends to respond to the adaptability to enhance better performance. Lecturers' 
adaptability and emotional intelligence which is in every individuals, it can enhance each lecturers' capabilities to selfdeveloped and to have a positive value in the workplace (Gupta, 2018).

\subsection{Lecturers Adaptability and Working Performance}

Adaptability does not mean to changing something, adaptability has to adapt from the pressure situation to change into a good situation; thus, the situation has changed (Banjongprasert, 2000). Adaptability is an art that has no limitations in the workplace. The strong arts of adaptability are accepting of obstacles that existed and find solutions for it and become a good leader. On the other hand, performance is a result of the assessment for every lecturer which is based on their performances on their job description (Sony \&Mekoth, 2016). Lecturers' performance is an indicator for each lecturer to assess their work and to achieve the necessary and objectives of the institution (Dipboye, 2018).

The special adaptability between individuals has been discussed in the literature review, and it has covered regarding inter-personal flexibility. Adaptability is an effective manner for each individual, employee tends to be flexible in their workplace and be responsible in every work in their workplace (Pulakos, et, al., 2000). Adaptability skills can help lecturers into a change in achieving the objectives and target of the institutions, and also it can enhance lecturers' performance. Moreover, the adaptability skill can help employees to understand well other employees in the context of adaptation capacities.

As a guide model, the inter-personal flexibility requires adopting effective team building among employees, flexibility in work, and be responsible for employees' work (Pulakos, $e t$, al., 2000). This is a good manner to be effective in teamwork (Pulakos, et, al., 2000)Therefore, university lecturers' adaptability has justified that it can enhance working productivity, adaptability capacity, and these are the strategy for lecturers to self-change to be good (Collie, et, al., 2020).

\subsection{Emotional Intelligence, Adaptability and University Lecturer's Performance}

University lecturers' adaptability knowledge has related to emotional intelligence and lecturers' performance. Emotional intelligence could help the lecturer to adopt in the new workplace. Emotional intelligence provided a positive effect on the adaptability capacities of lecturers' career. Emotional intelligence is a potential factor that contributes to the positive result of individuals' behavior, also EI acknowledges as thr capacity competent concept for every individual (Sony and Mekoth, 2016). Emotional intelligence is defined as social intelligence which means the ability to identify, assess, and control one's own emotions, the emotion of others, and that of groups. Lecturers' performance defines as lecturers have achieved their work in the workplace (Henseler, et, al., 2015). Lecturers' performance is the result of lecturers' assessment to determine whether lecturers are succeeded in their job or not.

Lecturers' performance has become the main factor that contributes to emotional intelligence and adaptability in an organization particularly in high education institutions. An organization that has acknowledged the lecturers' performance will support their lecturers emotional intelligence and adaptability. Thus, these institutions will have a good quality, and become high education institutions that tend to have complete human resources development and for sure, it will become an example for other higher private education institutions.

\subsection{Conceptual Framework}

The conceptual framework of this study is developed from all concepts which were defined in the problems and objectives of this research. This conceptual framework aimed to explain the details links regarding the topic of this research and the detailed discussions. This conceptual framework is also based on previous literature reviews or previous studies.

According to (Henseler, et, al., 2016). Mentioned that the conceptual framework is the connection concepts of theories for each variable, namely independent and dependent variables. The Figure 1, explain the conceptual framework of this research which is explained the factors influence to the working/job performance (dependent variable), they are emotional intelligence (independent variable) and working performance, and adaptability (independent variable) as the mediation variable for EI and working performances.

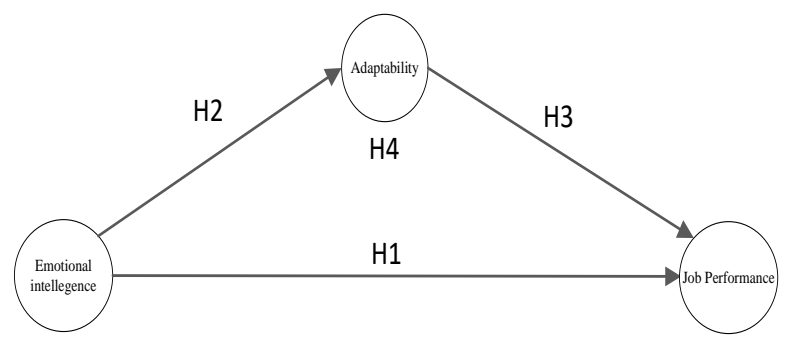

Figure 1. The Conceptual Framework

\subsection{Hypotheses}

Hypotheses are based on the concept of research problems and objectives. It is also based on the previous literature review. All perspectives and predictions were gathering in this data. Therefore, the following are hypotheses.

H1: Emotional intelligence has a positive effect on lecturers' performance.

H2: Emotional intelligence has a positive effect on lecturers' adaptability.

H3. Adaptability has a positive effect on lecturers' performance. $\mathrm{H} 4$ : Emotional intelligence has a positive effect on the adaptation and work performance of a lecturer.

\section{Methodology}

\subsection{Sample}

The sample in this study, with a population of 1690 lecturers from private tertiary institutions, (Godinho, et, al., 2013).This 
study was explorative research and was used as a margin error of $0.01 \%$. Therefore, the total sample was calculated as 94 from the total population.

\subsection{Techniques for Collecting the Data}

The survey was conducted by the researcher to achieve the objectives of this research. The data was determined with variables that hypothesized on the model. The variables were used based on the previous variables that have been used by previous researchers. The researcher adopted theories of EI proposed by (Sony \&Mekoth, 2016) and theories of adaptability proposed by (Wong \& Law, 2002). The performance (dependent variable) and independent variables were measured with five skalelikert from 1 (strongly disagree) to 5 (strongly agree). The pilot test was not conducted by the researcher because the previous researchers have validated all questions. Therefore there is no requirement to doubt the validity of the questions of the variables.

\subsection{Techniques for Analyzing the Data}

This study is quantitative research which was consisted of descriptive and inference statistics. The descriptive analysis was presented regarding the participants' perceptions of EI, adaptability, and performances, however, these perceptions were not used as the generalized ideas of the research. The descriptive analysis was presented with the percentage and mean of all responses. The descriptive analysis results are usually presented with frequency distribution in the tables or graphics. The inference analysis was used to measure the validity and reliability relations among items or variables, mediation, and inner model measurement.

The inference analysis was used to answer the hypotheses. SMART-PLS 3.0 was used as a tool to analyze the data, because it can be assessed to small sample size (30), formative or reflective indicators, multi-variety analysis of the variables and there is no requirement to further analyze the normality of the variables (Willy, 2015). This instrument is already approved to analyze many variables. Therefore, it can be used to analyze the relationships between many variables and small sample size. This analysis was divided into three parts. First, the analyzes were conducted regarding the relationships between indicators and variables. Second, the analysis was assessed for all variables in the PLS. Third, the analysis of the outer model or measurement model to validate the relationships and significant impact of the variables used path coefficient (test for T-statistic and P-value).

\section{Result}

\subsection{Reliability and Validity Test}

This study was tested using cronbach alpha (CA) and composite reliability (CR) to assess the reliability of each construct. The reliability test of cronbach alpha (CA) and composite reliability $(\mathrm{CR})$ indicated that the construct variables loadings should be exceeded than 0.70 . The result of this CA and CR test showed that all items are satisfactority exceeded 0.7 (see Table 4.1). Therefore, the models illustrated that all items are acceptable consistent as internal reliability.

\section{Table 4.1. Construct Reliability Result}

\begin{tabular}{cccc}
\hline Item & CA & CR & AVE \\
\hline CP & 0,759 & 0,847 & 0,582 \\
EF & 0,882 & 0,925 & 0,805 \\
IA & 0,839 & 0,886 & 0,610 \\
IF & 0,702 & 0,870 & 0,770 \\
OA & 0,905 & 0,934 & 0,779 \\
OE & 0,755 & 0,859 & 0,672 \\
RE & 0,815 & 0,878 & 0,642 \\
SAA & 0,862 & 0,906 & 0,707 \\
SE & 0,761 & 0,848 & 0,585 \\
SOA & 0,750 & 0,842 & 0,574 \\
TP & 0,768 & 0,852 & 0,591 \\
UE & 0,824 & 0,884 & 0,659 \\
\hline
\end{tabular}

\subsection{Validity Test}

There are two categories of validity; they are convergent validity and discriminate validity. Convergent validity is a validity analysis which is using outer leading (OL) and average variance extracted (AVE). An item measured with OL must be exceeded 0.7 and AVE must be exceeded 0.5 , therefore all items are exceeded than 0.7 for OL and 0.5 for AVE, thus all convergent test is valid (Hair, et, al,. 2014). However, for exploratory research, the OL value could be exceeded than 0.6 and this value does not influence the content validity. Table 4.1 showed that the AVE value for all items are exceeded 0.5. Therefore, all items is satisfactority acceptable for convergent validity to be further tested the relationships among all variables (inner model measurement).

The discriminate validity was assessed by Fornell-Larcker Criterion (FL) and Heterotrait-Monotrait (HTMT). When assessed by FL, all items construct considered valid when the value of square root of average variance extracted ( $\sqrt{\mathrm{AVE}})$, AVE the correlation between each constructs has higher loadings than AVE 0.5 ( Hair. J, et, al., 2017). The square roots of the AVE of PLMF are highest than other items (See Table 4.2). The FL assessed for discriminate validity indicated that all items loadings meet the threshold requirements (Hair, et, al., 2017). The minimum value is SE, 4 (0.647). Therefore, based on the FL result, all indicators or measurement model has satisfactory discriminate validity. 
Vol.2, Issue 1, pp. 45-55, 2020 Available online at: https://tljbm.org/jurnal/index.php/tljbm

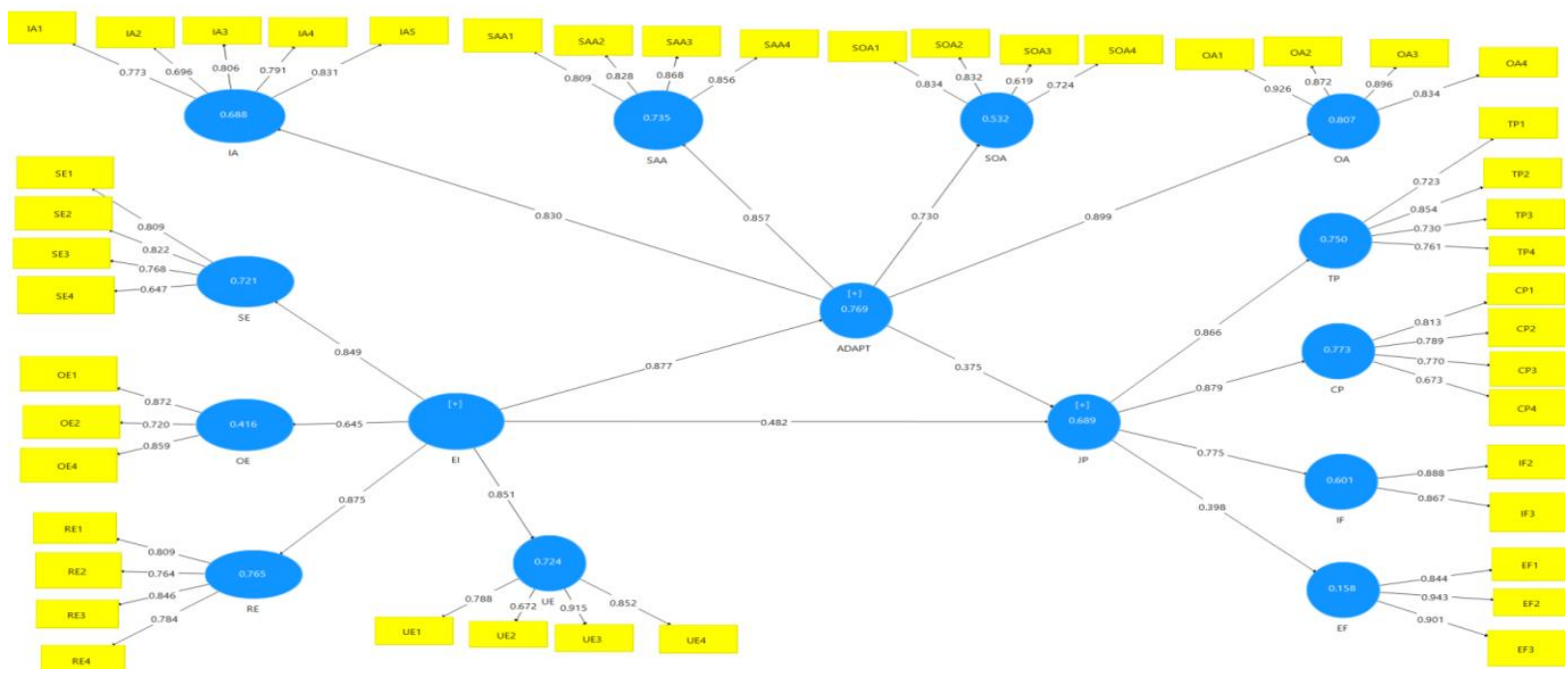

Figure 2. Indicators Loading for Convergent Validity.

Table 4.2. Fornell-Larcker Criterion Value

\begin{tabular}{|c|c|c|c|c|c|c|c|c|c|c|c|c|}
\hline Item & $\overline{\mathrm{CP}}$ & $\overline{E F}$ & IA & IF & $\mathbf{O A}$ & $\overline{\mathrm{OE}}$ & RE & $\overline{\text { SAA }}$ & $\overline{\text { SE }}$ & SOA & TP & $\mathbf{U E}$ \\
\hline$\overline{\mathrm{CP}}$ & 0,763 & & & & & & & & & & & \\
\hline EF & 0,215 & 0,897 & & & & & & & & & & \\
\hline IA & 0,595 & 0,169 & 0,781 & & & & & & & & & \\
\hline IF & 0,553 & 0,228 & 0,487 & 0,878 & & & & & & & & \\
\hline OA & 0,677 & 0,222 & 0,659 & 0,506 & 0,883 & & & & & & & \\
\hline OE & 0,382 & 0,113 & 0,480 & 0,356 & 0,416 & 0,820 & & & & & & \\
\hline RE & 0,653 & 0,231 & 0,670 & 0,480 & 0,738 & 0,430 & 0,802 & & & & & \\
\hline SAA & 0,614 & 0,169 & 0,611 & 0,430 & 0,736 & 0,396 & 0,718 & 0,841 & & & & \\
\hline SE & 0,661 & 0,166 & 0,505 & 0,497 & 0,679 & 0,504 & 0,614 & 0,627 & 0,765 & & & \\
\hline SOA & 0,578 & 0,201 & 0,489 & 0,449 & 0,547 & 0,484 & 0,494 & 0,503 & 0,557 & 0,758 & & \\
\hline TP & 0,670 & 0,251 & 0,620 & 0,528 & 0,589 & 0,388 & 0,670 & 0,555 & 0,594 & 0,470 & 0,769 & \\
\hline UE & 0,596 & 0,219 & 0,650 & 0,471 & 0,708 & 0,395 & 0,689 & 0,696 & 0,637 & 0,330 & 0,645 & 0,812 \\
\hline
\end{tabular}

Also, to test the discriminate validity, the measurement of the Heterotrait-Monotrait Ratio (HTMT) was utilized to assess all items, and it should be exceeded the lowest loading below 0.85 (Hair, j, et al., 2010). The result indicated that the loading of
HTMT for all measurement models less than 0.85 (See Table 4.3). Therefore, all items in this measurement model have also satisfactory discriminate validity. 
Table 4.3. Heterotrait-Monotrait Ration (HTMT)

\begin{tabular}{lllllllllllll}
\hline Item & CP & EF & IA & IF & OA & OE & RE & SAA & SE & SOA & TP & UE \\
\hline EF & 0,261 & & & & & & & & & & & \\
IA & 0,738 & 0,182 & & & & & & & & & & \\
IF & 0,750 & 0,281 & 0,636 & & & & & & & & & \\
OA & 0,812 & 0,229 & 0,750 & 0,636 & & & & & & & & \\
OE & 0,493 & 0,156 & 0,603 & 0,481 & 0,483 & & & & & & & \\
RE & 0,812 & 0,252 & 0,795 & 0,627 & 0,843 & 0,537 & & & & & & \\
SAA & 0,740 & 0,191 & 0,703 & 0,548 & 0,825 & 0,488 & 0,850 & & & & & \\
SE & 0,861 & 0,239 & 0,625 & 0,666 & 0,812 & 0,634 & 0,760 & 0,760 & & & & \\
SOA & 0,757 & 0,272 & 0,620 & 0,591 & 0,644 & 0,626 & 0,607 & 0,596 & 0,716 & & & \\
TP & 0,869 & 0,304 & 0,765 & 0,705 & 0,707 & 0,497 & 0,839 & 0,672 & 0,764 & 0,606 & & \\
UE & 0,736 & 0,257 & 0,768 & 0,607 & 0,815 & 0,492 & 0,824 & 0,814 & 0,807 & 0,394 & 0,786 & \\
\hline & & & & & & & & & & & & \\
\hline
\end{tabular}

\subsection{Hypotheses Test}

The hypotheses test was using the T-statistic and P-value in the path coefficient test. The hypotheses would be positive if the T-statistic value exceeded than 1.96 and a significant Pvalue of less than 0.05 (Raza et al., 2020). In this research, the first hypothesis is EI (Emotional Intelligence) would have a positive significant effect on working performance. The result in SMART-PLS 3.0 showed that the T-statistics value is (3.750; $\mathrm{p}=0.000$ ) (see Table 4.4). This means EI does not reflect as a risk for pro-active innovation to lecturers on their working performances in the higher private education institutions in Timor-Leste. Therefore, H1 is supported.

The second hypothesis is the EI would have a positive significant effect on lecturers' adaptability. The result in SMART-PLS 3.0 showed that the T-statistics value is (25.732; $\mathrm{p}=0.000$ ) (see Table 4.4). This means the T-statistic exceeded 1.96 and the $\mathrm{p}$ value less than 0.05 . Thus, $\mathrm{H} 2$ is also supported.

Table 4.4. Direct Effect of Path Coefficient Result

\begin{tabular}{lccccc}
\hline & $\begin{array}{c}\text { Original } \\
\text { Sample } \\
(\mathbf{O})\end{array}$ & $\begin{array}{c}\text { Sample } \\
\text { Mean } \\
(\mathbf{M})\end{array}$ & $\begin{array}{c}\text { Standard } \\
\text { Deviation } \\
(\text { STDEV })\end{array}$ & $\begin{array}{c}\text { T Statistics } \\
(\mid \mathbf{O} / \text { STDEV })\end{array}$ & P Values \\
\hline EI -> JP & 0,482 & 0,514 & 0,129 & 3,750 & 0,000 \\
EI -> ADAPT & 0,877 & 0,889 & 0,034 & 25,732 & 0,000 \\
ADAPT -> JP & 0,375 & 0,355 & 0,139 & 2,699 & 0,007 \\
EI -> ADAPT -> JP & 0,328 & 0,317 & 0,128 & 2,575 & 0,010 \\
\hline
\end{tabular}

The third hypothesis is lecturers' adaptability would have a positive significant effect on working performances. The result in SMART-PLS 3.0 showed that the T-statistics value is (2.699; $\mathrm{p}=0.000$ ). This means the T-statistic exceeded 1.96 and the Pvalue less than 0.05 (see Table 4.4). Therefore, the value of T- statistic and P-values met the thresholds (Sony and Mekoth, 2016). This means there is a positive significant effect of lecturers' adaptability on lecturers' working performances. Thus, H3 is also supported. 


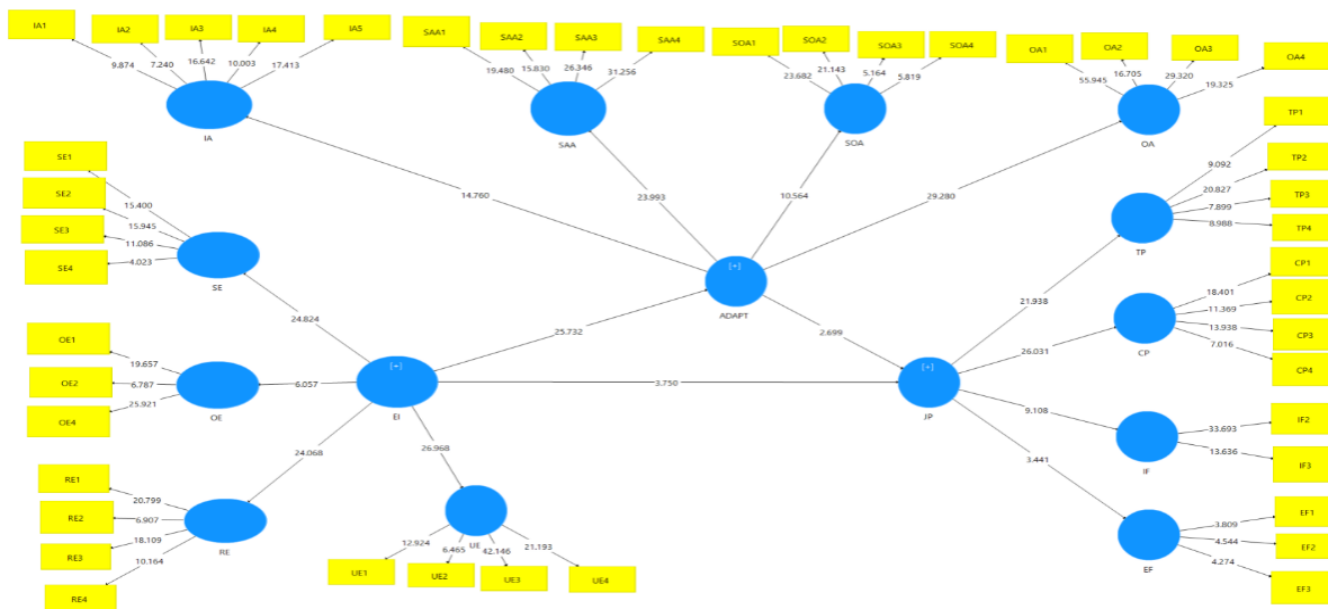

Figure 3. Path Coefficient

The fourth hypothesis is the role of emotional intelligence adaptation and lecturer work performance. The SMARTPLS 3.0 results on the specific indirect effect showed that the T-statistic was $(2.575 ; \mathrm{p}=0.010)$. This also means that the T-statistic exceeds 1.96 and the p value is less than 0.05 (see Table 4.4), adaptability plays an important role. as emotional intelligence, and lecturer performance. So, $\mathrm{H} 4$ is also supported.

\section{Discussions}

The higher private education institutions are universities that educate and prepare a young generation for working. The total number of lecturers in the higher private education institutions is 1690 , it is a huge number; therefore, lecturers need to work hard in teaching and preparing new generations to be well educated. Lecturers' performance is one of the strong indicators to assess the lectures' capabilities in an institution. Lecturers in an institution must maximize his/her productivity in teaching and learning. The main objective of this research is to investigate the influence of variables EI (Emotional Intelligence) and adaptability on lecturers' performance. To investigate and find solutions to the problems referred; therefore, this survey was conducted to 94 samples as participants, which is consisted of 66 men and 28 women. Emotional intelligence has four items, they are self-emotional, other emotional, regulation of the emotion and use of emotional. This means that there is a relationship between an individual with others to control an individual's emotion in their work area (Sembiring, et, al., 2020). This result is consistent with the previous study which illustrated that there is a positive significant relationship between the measurement of team capacity and emotional intelligence as the objective of this study. This means EI has proven as one of the main indicator contributions as it has a positive significance on lectures' performance in the higher private education institutions in Timor-Leste. This also means that lecturers in the private universities in Timor-Leste have made a contributed to their university (Clarke, 2010).

The results of this study also indicate that emotional intelligence has a significant positive effect on adaptability. This means that university lecturers need to have better adaptability with other university lecturers, moreover all lecturers need to have good cooperation in improving the lecturer's work performance; to improve the quality of higher education in the future. This also means the private universities require to acknowledge techniques on adaptability, particularly interpersonal adaptability, and managerial adaptability to create the plan and implementation for the better teaching materials and have unique value teaching facilities. Adaptability is mainly obtained from learning, training, and experience. Therefore, the university could enhance lecturers' performance through by providing training for lecturers. The unique value must be fostered to ensure competitiveness by developing teaching plan and strategies. The result of this study showed that EI and adaptability variables have a positive significance on lecturers' performance. This means lecturers focus on their work, and they showed how important of EI and adaptability for their performances.

This result of this study is consistent with the previous study of EI and work adaptation capabilities. The result underlined that adaptation is important in a job or workplace. Therefore, the result of this study also showed that there is a positive significant relationship between EI and adaptability. Thus, H2 is supported.

This concludes that there is a positive significant relationship between EI and adaptability. This also means the relationships between EI and adaptability on individual capabilities are significant which could enhance an individual's knowledge of EI and also could naturally express the EI. The result of this study illustrated that the important lecturers' quality is the emotion assessment that showed positive relationships with adaptation capabilities. 
The result of this study showed that items of adaptability had a positive significance on working performance (see Table 4.8). Therefore, $\mathrm{H} 3$ is also supported. Lecturers' performance means good manner of working which based on lecturers' responsibilities and achieve the objectives effectively. Items or indicators of lecturers' performance which were mediated EI in the private universities in Timor-Leste. Based on the previous explanation, the result shows and concludes that lecturers in private universities tend to perform well in their job, and another reason is because most of lecturers have been working for more than ten years. Therefore, those lecturers tend to score high on EI which lead to better teaching performances.

H4 described the positive relationships between the assessment of EI and adaptability. People's emotional assessment and capabilities assessment have a relationships with one and another. In order to know people emotions, it could be visible through work, research, and feeling of communication. Previous study also found that there is a positive relationships between emotion and communication (Zulfadil, 2019b). This study illustrated that emotions showed from the result of the assessment of working. Therefore, the result of this study supported the significant relationships between EI and adaptability on working performance.

Finally, this research comes with conclusions as the objective of this study was to explore the relationships between EI and adaptability on job or working performance. This study confirmed that there is a positive impact of EI and adaptability, and also adaptability played as important role for mediation between EI and performances. The result of this study also comfirmed that there is a positive relationships between adaptability and performances. This study has provided relevant and interesting perceptions of adaptability which is important knowledge of it. Overall, this is the first study conducted in higher private education institutions in Timor-Leste.

\section{Conclusions and Implications}

Three items of performances have shown the good result. First, the task performance has got the highest value. Then, it is followed by task constitute which score higher on the mean value. Lastly, the extrinsic factor have got least value. This shows that performances have a positive relationship significant among the lecturers' performances in the private universities in Timor-Leste. Particularly, this research have accomplished and addressed all objectives as follows:

EI (emotional Intelligence) has a positive significant related to work performance. The most EI factors (from the highest to the lowest) that contributed to work performance are regulation of emotional, use of emotional, self-emotional, other emotional. This means EI does not reflect from the risk, it requires innovation and pro-active from lecturers in order to enhance lecturers' performance in the private universities in Timor-Leste.

EI (Emotional Intelligence) also has a positive significant influenced adaptability. This means this result with support the private universities in Timor-Leste to self -foster their institutions and ensure the lecturers' performance in future.
Adaptability has a positive significant on performance. This is because when lecturers have adaptability in their workplace, they tend to redefine their motivation, observe and learn, ask questions if they doubt with something, prepare alternative solutions, stay calm and confident, acquire new skills and set small goals. Therefore, those lecturers tend to perform well and achieve their objectives in their universities.

EI (Emotional Intelligence) has a positive significant influenced adaptability and related to performances. Based on the result of this study, it shows that variables of EI and adaptability are significant to performances.

For the theoretical implications, this study would recommend as follows:

This study's survey were used questionnaire for participants to fill in, it might cause bias when respondents just fill in without further reading and understand questions. Therefore, it is recommended for the future research to add interview besides doing survey on questionnaires. This research applied the margin error $0.01 \%$; thus, it is recommended for future research to apply the same margin error percentages. Therefore, it could enhance the confidence on the conclusions with all relationships among variables. This research is the first research conducted in Timor-Leste. Therefore, it is recommended for the future research to conduct the same research on EI, adaptability and performances in other areas.

Based on the result of this study, there are some recommendation for the higher private education institutions in Timor-Leste as follows:

Higher private education institutions is the important high education to support the pro-active youth in the future in order to achieve youth's dreams and family needs. The high education could help the youth (students) to be ready to work in their field or to be entrepreneurs (owner of their own work). Government needs to develop rules and regulations to facilitate resources in the high education. Therefore, the high education could have better learning and teaching process. Government also requires to maximize providing subsidies and facilities to the high education.

The high education should keep maintaining their vision and mission to enhance the capabilities of their lecturers. The lecturers require to obtain their high level of education for master degree and doctoral degree. Therefore, those lecturers could transform the knowledge better to students. Lecturers also could motivate students in their teaching; thus, university students are ready to serve the community and the country in future. The high education institutions in Timor-Leste continue developing all specific values of all intellectual factors that related to lecturers and lecturers, also lecturers to students.

Finally, the high education institutions need to support their lecturers in enhancing their capabilities. The support for lecturers could be provided through training, build good communication between lecturers and students or lecturers and lecturers or lecturers and leaders of high education institutions. This is because miss communication will lead to negative impact on teaching and learning process in the high education institutions. 


\section{Limitation and Future Research}

The limitation of this study is the study only conducted for the 10 higher private education institutions in Timor-Leste. The total population was 1960 (based on the report from ANAAA 2013-2018). This study was also focused on the EI, adaptability and lecturers' performances only in TL. The sample used was only 94 . Therefore, it was not maximized the total numbers of the population. This research also only used questionnaire as survey responds from the respondents. Therefore, for the future research it could be done by interviewing or direct observation to reflect the quality of the research and the result. Moreover, for the future research the study could involve the public university as well. This study is the first study to the private university in Timor-Leste; thus, it could be a guide for the future research to continue it in order to obtain the better result.

\section{Reference}

Abu Elnasr E. Sobaiha, b Y. (2019) 'Unlocking the black box: Psychological contract fulfillment as a mediator between HRM practices and job performance', 30, pp. 171-181.

Adika, F. O. and Kwanya, T. (2020) 'Research data management literacy amongst lecturers at Strathmore University, Kenya', Library Management.

Ala'aldin Alrowwad, S. H. A. and Manag, D. of (2020) 'Innovation and intellectual capital as intermediary variables among transformational leadership, transactional leadership, and organizational performance', Journal of Management Development, 39(2), pp. 196-222.

Banjongprasert, J. (2000) 'The Study of Individual-Level Adaptability and Service Innovation Performance.'

Castillo, M. A. S. and Del valle, I. D. (2017) 'Is emotional intelligence the panacea for a better job performance? A study on low-skilled back office jobs.', emerald insight.

Cladera, M. (2020) 'Let's ask our students what really matters to them'.

Collie, Rebecca J, Martin, A. (2020) 'Adaptability among science teachers in schools: A multi-nation examination of its role in school outcomes', Teaching and Teacher Education. Elsevier Ltd, 95.

Darvishmotevali, M., Altinay, L. and Vita, G. De (2018) 'Emotional intelligence and creative performance: Looking through the lens of environmental uncertainty and cultural intelligence', International Journal of Hospitality Management. Elsevier, 73, pp. 44-54.

Dipboye, R. L. (2018) Work Motivation, The Emerald Review of Industrial and Organizational Psychology.

Freitas Joao, C. (2015) 'Report from the Minister of Education in Timor-Leste'.

Godinho, C. (2013) Agência Nacional Para A Avaliação Acreditação Académica. Timor-Leste.
Goleman (20018) 'Emotional Intelligence', Googel.com.

Gupta, M. (2018) 'Does work engagement mediate the perceived career support- and career adaptability- work performance relationship ?', Emerald Insight.

Hair, J. et al. (2017) 'An updated and expanded assessment of PLSSEM in information systems research', Industrial Management \& Data Systems, 117(3), pp. 442-458.

Hair, J. F. et al. (2010) Multivariate Data Analysis. Seventh ed.

Hair, J. F. et al. (2014) 'Partial least squares structural equation modeling (PLS-SEM)', European Business Review, 26(2), pp. 106-121.

Henseler, J., Ringle, C. M. and Sarstedt, M. (2015) 'A new criterion for assessing discriminant validity in variance-based structural equation modeling', Journal of the Academy of Marketing Science, 43(1), pp. 115-135. doi: 10.1007/s11747-014-0403-8.

Henseler, J., Ringle, C. M. and Sarstedt, M. (2016) 'Testing measurement invariance of composites using partial least squares', International Marketing Review, 33(3), pp. 405-431. doi: 10.1108/IMR-09-2014-0304.

Kivipõld, K., Türk, K. and Kivipõld, L. (2020) 'Performance appraisal, justice and organizational effectiveness: a comparison between two universities', International Journal of Productivity and Performance Management.

Mekoth, S. and (2016) 'Job satisfaction and job performance in the media industry 'Job satisfaction and job performance in the media industry.', emeraldinsinght, 28(5).

Miguel Ángel Sastre Castillo, I. D. D. V. (2018) 'is emotional intelligence job performance.'

Miotto, G., Del-Castillo-Feito, C. and Blanco-González, A. (2020) 'Reputation and legitimacy: Key factors for Higher Education Institutions' sustained competitive advantage', Journal of Business Research. Elsevier, 112, pp. 342-353.

Available at: https://doi.org/10.1016/j.jbusres.2019.11.076.

Mittal, S. (2020) 'Ability-based emotional intelligence and career adaptability: role in job-search success of university students', Higher Education, Skills and Work-based Learning.

Ni Made Ayu Yasmitha, Putra, Andewi, Wayan Gede Supartha, M. S. (2016) 'pengaruh kecerdasan emosional terhadap stes kerja dan kepuasan kerja', Jurnal Ekonomi dan Bisnis Universitas.

Pulakos, E.D., Arad, S., Donovan, M.A., Plamondon, K. . (2000) 'Adaptability in the workplace: development of a taxonomy of adaptive performance. J. Appl'.

Rajalakshmi, M. and Naresh, B. (2018) "'Workplace bullying: behaviour and impact", International Journal of Cyber Behavior, Psychology and Learning', 118(18), pp. 4481-4495.

Raza, A. et al. (2020) 'An assessment of corporate social responsibility on customer company identification and loyalty in banking industry: a PLS-SEM analysis', Management Research 
Review.

Riane Johnly Pio, J. R. E. T. (2018) 'The influence of spiritual leadership on quality of work life, job satisfaction and organizational citizenship behavior'.

Sakyi, E. K. and Agomor, K. S. (2020) 'Moonlighting in Ghana's higher education institutions: exploring lecturers' experiences at the Ghana Institute of Management and Public Administration (GIMPA)'

Sembiring, N. et al. (2020) 'The effects of emotional intelligence and organizational justice on job satisfaction, caring climate, and criminal investigation officers' performance', International Journal of Organizational Analysis.

Sony, M. and Mekoth, N. (2016) 'The relationship between emotional intelligence, frontline employee adaptability, job satisfaction and job performance', Journal of Retailing and Consumer Services. Elsevier, 30, pp. 20-32.

Srivastava, S. and Dey, B. (2020) 'Workplace bullying and job burnout: A moderated mediation model of emotional intelligence and hardiness', International Journal of Organizational Analysis, 28(1), pp. 183-204.

Treasa Gianfranco, K. (2017) 'Emotional intelligence in frontline/back-office employee relationships-', Journal of Services Marketing, 31(2)

Wong, L. \& (2012) 'The effects of leader and follower emotional intelligence on performance and attitude'.

Yimin, H., Donnellan, M. B. and Mendoza, A. M. (2019) 'Fivefactor personality domains and job performance: A second order meta-analysis', Journal of Research in Personality. Elsevier Inc., 82.

Zulfadil, S. H. and M. (2019) 'The influence of emotional intelligence on team performance through knowledge sharing, team conflict, and the structure mechanism', Journal of Management Development, 39(3), p. 269.292.

Zulfadil, S. H. and M. (2020) 'The influence of emotional intelligence on team performance through knowledge sharing, team conflict, and the structure mechanism'. 